2011-07-11

\title{
Promoting Couples Collaboration in Type 2 Diabetes: The Diabetes Support Project Pilot Data
}

\author{
Paula Trief \\ SUNY Upstate Medical University \\ Jonathan G. Sandberg \\ Brigham Young University - Provo, jonathan_sandberg@byu.edu \\ Robert Ploutz-Snyder \\ SUNY Upstate Medical University \\ Rebecca Brittain \\ SUNY Upstate Medical University \\ Donald Cibula

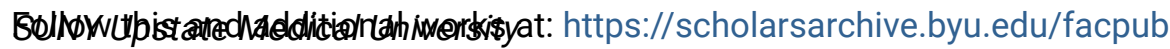 \\ Part of the Other Social and Behavioral Sciences Commons
}

See next page for additional authors

Original Publication Citation

Trief, P.M., Sandberg, J.G., PhD, Ploutz-Snyder, R., Brittain, R., Cibula, D., Scales, K., Weinstock, R.S. (2011). Promoting couples collaboration in type 2 diabetes: The Diabetes Support Project pilot data. Families, Systems, and Health, 29(3), 253-261.

\section{BYU ScholarsArchive Citation}

Trief, Paula; Sandberg, Jonathan G.; Ploutz-Snyder, Robert; Brittain, Rebecca; Cibula, Donald; Scales, Kasandra; and Weinstock, Ruth S., "Promoting Couples Collaboration in Type 2 Diabetes: The Diabetes Support Project Pilot Data" (2011). Faculty Publications. 4075.

https://scholarsarchive.byu.edu/facpub/4075

This Peer-Reviewed Article is brought to you for free and open access by BYU ScholarsArchive. It has been accepted for inclusion in Faculty Publications by an authorized administrator of BYU ScholarsArchive. For more information, please contact ellen_amatangelo@byu.edu. 


\section{Authors}

Paula Trief, Jonathan G. Sandberg, Robert Ploutz-Snyder, Rebecca Brittain, Donald Cibula, Kasandra Scales, and Ruth S. Weinstock 


\title{
BRIEF REPORT
}

\section{Promoting Couples Collaboration in Type 2 Diabetes: The Diabetes Support Project Pilot Data}

\author{
Paula Trief, PhD \\ Jonathan G. Sandberg, PhD \\ Robert Ploutz-Snyder, PhD \\ Rebecca Brittain, MA \\ Donald Cibula, PhD \\ Kasandra Scales, MPH \\ Ruth S. Weinstock, MD, PhD
}

A pilot study was conducted to assess the feasibility and potential efficacy of a couples focused diabetes intervention in which a collaborative problem-solving approach to diabetes self-care was promoted. Couples $(\mathrm{N}=$ 44), in which one partner had Type 2 diabetes and was in poor blood glucose control were randomly assigned to one of three groups: a

This article was published Online First July 11, 2011.

Paula Trief, PhD, Department of Psychiatry, SUNY Upstate Medical University; Robert PloutzSnyder, PhD, and Rebecca Brittain, MA, Department of Medicine, SUNY Upstate Medical University; Donald Cibula, PhD, Department of Public Health and Preventative Medicine, SUNY Upstate Medical University; Kasandra Scales, MPH, Department of Psychiatry, SUNY Upstate Medical University; Ruth S. Weinstock, MD, PhD, Department of Medicine, SUNY Upstate Medical University; and Jonathan G. Sandberg, PhD, School of Family Life, Brigham Young University.

This study was funded by the National Institute of Diabetes, Digestive and Kidney Diseases of the National Institutes of Health. ClinicalTrials.gov \#NCT00250731.

Correspondence concerning this article should be addressed to Paula Trief, PhD, Department of Psychiatry, SUNY Upstate Medical University, Syracuse, NY 13210. E-mail: triefp@upstate.edu couples intervention, an individual intervention, or individual diabetes education. The intervention included goal-setting, dietary behavior change, and a focus on emotions. For those in the couples arm, this was done within the framework of promoting collaborative communication between the partners. All intervention contacts were over the telephone to increase reach. Results showed that both the individual and couples interventions yielded meaningful clinical improvements in medical outcomes. Diabetes education also resulted in improved blood glucose control. Despite the small number, mixed-model regression analyses found statistically significant treatment effects for total cholesterol. This pilot demonstrates the feasibility and potential efficacy of a telephone intervention for Type 2 diabetes patients and their partners. Information from implementing this pilot led to refinement and further development of the intervention, which is being assessed in a larger, more comprehensive trial.

Keywords: Type 2 diabetes, couples intervention, glycemic control 
$\mathrm{T}$

The Diabetes Control and Complications Trial (Diabetes Control \& Complications Research Group, 1993) and the United Kingdom Prospective Diabetes Study (United Kingdom Prospective Diabetes Study Group, 1998) have convincingly demonstrated that intensive blood glucose (glycemic) control can reduce or forestall serious diabetes-related complications. However, innovative interventions need to be developed that can maximize successful translation of these findings into practice (Garfield, Malozowski, Chin et al., 2003).

Studies of Type 2 diabetes patients report that marital and family support relates to blood glucose control, adherence to diabetes self-care regimens, and quality of life (Garay-Sevilla et al., 1995; Trief, Himes, Orendorff, \& Weinstock, 2001; Trief, Ploutz-Snyder, Britton, \& Weinstock, 2004; Trief, Wade, Britton, \& Weinstock, 2002). The impact of family variables may be particularly strong in diabetes management, where the self-care regimen (e.g., food purchase and preparation, medication administration) often involves partners (Delamater et al., 2001; GonderFrederick, Cox, \& Ritterbrand, 2002). Therefore, interventions that target couples may improve outcomes (Fisher, 2006; Fisher \& Wiehs, 2000; Schmaling \& Sher, 2000).

Despite the acknowledged importance of partner support, interventions almost always target the individual. The limited studies that have linked marital interaction and health, or have suggested models for intervention, provide limited, and disappointing, data on the effect of couples based interventions on health outcomes (Schmaling \& Sher, 2000). Martire and colleagues performed a meta-analysis of studies that assessed the benefit of family interventions for chronic illness patients. Looking at patient outcomes, they found a positive effect on depression when the spouse was included, but no effect on anxiety, physical disability or relationship satisfaction (Martire, Lustig, Schulz, Miller, \& Helgeson, 2004). They also found that decreased mortality was an outcome of family interventions but only when the intervention was not limited to spouses and did not address relationship issues. Their more recent review of couples oriented interventions across various diseases (e.g., cancer, arthritis) concludes that there is evidence that couples interventions can have significant, albeit small, effects on marital functioning, patient depressive symptoms and pain (Martire, Schulz, Helgeson, Small, \& Saghafi, 2010). Black and colleagues performed a meta-analysis of couple versus individual weight loss interventions and did find a significant, again small and short-lived, benefit of the interventions that included partners (Black, Gleser, \& Kooyers, 1990). However, deVoogd and colleagues' (deVoogd, Knipping, deBlecourt, \& vanRijswijk, 1993) study of marital therapy and group psychomotor therapy to treat fibromyalgia patients and their spouses found no significant difference between control and treatment groups. Similarly, smoking cessation interventions that have tried to enhance spousal support to promote behavior change have not shown significant changes in perceived support or benefits that could be attributed to spousal support (Palmer, Baucom, \& McBride, 2000; McBride et al., 2004).

There have been no published randomized trials of couples interventions targeted at diabetes patients. In one, uncontrolled study of elderly diabetes patients, Gilden and colleagues (Gilden, Hendryx, Casia, \& Singh, 1989) found that those whose spouses also participated in diabetes education showed greater improvement in diabetes knowledge, metabolic control, and stress level than those who participated alone. In one randomized weight loss intervention study, obese women, but not men, with diabetes lost more weight if they participated with their obese spouses than if 
they participated alone (Wing, Marcus, Epstein, \& Jawad, 1991).

\section{CONCEPTUAL APPROACHES TO COUPLES INTERVENTIONS}

The couples interventions cited earlier are based on the assumption that including the partner in the intervention will lead to greater spousal support, which will in turn lead to better patient health outcomes. After an extensive literature review, Lewis and colleagues have concluded that this model is overly simplistic and adherence to this model, and its reliance on spouse participation, may explain why couples interventions have not demonstrated better efficacy (Lewis et al., 2006). They argue that interventions should adopt a "dyad-level" model, that is, take into account the behaviors, feelings, thoughts, and motivations of both members of the dyad. Such an approach, based on Interdependence Theory (Kelley \& Thibaut, 1978), recognizes the "interdependence" of partners, so that it is the interaction between the partners that affects both members of the dyad, not simply the behavior of one partner affecting the behavior of the other. Both Family Systems Theory (Von Bertalanffy, 1968), which posits that change in one family member influences all others, and that successful adaptation to chronic illness can be promoted by focusing on the family system as the unit of intervention (Patterson \& Garwick, 1994), and Interdependence Theory form the theoretical bases of the intervention we will describe. The basic assumption is that partners must cope communally, first by agreeing that collaboration is helpful, by effectively communicating what they each can do, and by talking about problems as they arise. If either feels that the patient should do it alone, then spousal involvement will be irrelevant. Or, if their efforts result in greater conflict, spousal involvement will not be effective. A 'dyad-model' incorporates the behaviors, feelings and motivations of the patient and the partner and thus aims to promote "communal coping" (Rusbult \& Van Lange, 2003). Evidence that couples with conflictual communication patterns are at greater risk for cardiovascular problems, and experience immune and endocrine system suppression during times of conflict (Kiecolt-Glaser \& Newton, 2001; Robles \& Kiecolt-Glaser, 2003) supports the potential value of an intervention whose focus is on improved communication and collaborative problem-solving.

Most behavior change interventions are based on basic principles of Social Learning Theory (Bandura \& Walters, 1963). They are: (1) behavior change occurs as the result of reciprocal determinism, a dynamic interplay between the individual's thoughts, emotions and actions, and environmental influences; (2) the likelihood of a behavior is dependent on its reinforcement; (3) the likelihood of a behavior depends on the individual's expectations; (4) individuals can learn vicariously by observing others and are most likely to model the behavior of others with whom they have an emotional attachment (observational learning/modeling); (5) individuals are most likely to engage in a behavior for which they have high self-efficacy; and (6) behavior change rests on sufficient knowledge/skills to perform the behavior (behavioral capability). These principles have translated into the key components of health behavior change interventions that include behavioral contracting, self-monitoring, realistic and incremental goalsetting, knowledge development, and provision of social support for change (Shumaker, Schron, Ockene, \& McBee, 1998). Interdependence Theory does not contradict these tenets, but instead builds on them, by bringing the partner into the interaction, and involving him or her in each step of the process. The intervention we will describe was developed using these theoretical foundations.

Recruitment of couples is often limited by accessibility barriers. Telephone diabetes counseling has been effectively used to 
enhance feasibility and reach (Dale, Caramlau, Sturt, Friede, \& Walker, 2009; Sacco, Malone, Morrison, Friedman, \& Wells, 2009). The intervention we will describe was designed to be delivered over the telephone to address these accessibility barriers.

We report results of a pilot study to assess the acceptability, feasibility, and potential efficacy of, an innovative, theoretically based, behavior change couples intervention. We developed the intervention for this pilot and results have been used to further develop and refine the intervention for a larger, more comprehensive trial that is currently ongoing. Based on theory and prior research we hypothesized that the couples intervention would result in greater, and more lasting, improvement in our primary outcome, glycemic control, than either an individual intervention or diabetes self management education alone (enhanced usual care).

\section{METHOD}

\section{Participants}

There were $N=60$ couples, recruited by letter and advertisements, enrolled. They were both $>21$ years of age, had been married or partnered for $>1$ year, and the target subject had Type 2 diabetes in poor glycemic control. Poor glycemic control was defined as a measured hemoglobin A1c $\geq$ 7.3\%. Hemoglobin A1c, or A1c, is a measure of blood glucose control over the past 2-3 months, $<7.0 \%$ is a common goal for Type 2 diabetes patients, where higher numbers represent poorer glycemic control. Of the 142 telephone-screened, 82 were excluded because their A1c was too low, or they had no willing partner. Of the 60 assessed, 16 were excluded because their A1c was too low, or they failed to begin the intervention. The final sample $(N=44)$ included 28 females and 16 males, average age of $59.9( \pm 10.2)$ years, average education of $14.1( \pm 2.3)$ years, and average years with diabetes of $13.4( \pm 11.0)$ years. The groups did not differ on baseline measures, except that, despite randomization, the Individual group had a shorter duration of diabetes.

\section{Intervention}

Participants were randomly assigned to a couples intervention ("Couples"), individual intervention ("Individual") or Enhanced Usual Care (EUC) that consisted of two diabetes education sessions plus meal plan review. A study-trained Certified Diabetes Educator used a study-designed workbook to deliver two diabetes self-management education sessions and meal plan review, via telephone, to all participants. Then, intervention participants had 9 additional sessions focused on individualized goal-setting toward dietary behavior changes. In the Couples group, patients and partners participated in exercises to promote collaborative problemsolving as they worked on their goals. This included two calls that focused on couples' communication, especially around emotions and situations that might be problematic for the diabetes patient, so that the partner could share his or her feelings and they would discuss ways to problem solve together. The phone contact was fully interactive, the two partners were on a speakerphone. The homework and discussion tasks involved both partners in goal-setting, contracting and skills to improve couples communication. In addition, when they talked on the phone this same interactive process was facilitated by the interventionist. In the Individual group, patients participated alone. The two sessions that focused on communication in the Couples group addressed emotions about having diabetes that the individual might experience in the Individual group. These two calls were facilitated by a marriage and family therapist for both intervention groups.

\section{Measures}

Baseline, postintervention (3 months) and 6 month assessments were conducted by an assessor who was blind to group 
membership. Blood pressure, total and LDL cholesterol (fingerstick blood test), and waist circumference data were gathered systematically. Other measures included:

1. Glycemic control, as assessed by hemoglobin A1c (or A1c). A1c was analyzed using the DCA 2000, a wellaccepted point-of-care hemoglobin A1c analyzer. A1c reflects average blood glucose readings over the preceding 2-3 months and is widely accepted as a reliable and valid index of glycemic control (Nathan, Singer, Hurxthal, \& Goodson, 1984). A higher value represents poorer glycemic control.

2. Summary of Diabetes Self-Care Adherence scale (Toobert, Hampson, \& Glasgow, 2000). The patient selfreports adherence to recommended blood glucose testing, dietary control (calories and diet composition), exercise and foot care. The SDSCA has been shown to be a valid and reliable measure of diabetes self-management in multiple trials (Toobert, Hampson, \& Glasgow, 2000). We used the items that assessed diet and blood glucose testing with a higher score indicating more days that the participant performed self-care activities.

\section{STATISTICAL ANALYSIS}

Despite the small number, we performed longitudinal statistical analyses on the available data. We used mixed-effects regression techniques (Brown \& Prescott, 2006) using Stata/IC (StataCorp, 2009) software to examine longitudinal changes by groups on all available data from our final $N=44$ (four couples provided only partial data). Models included fixed-factor indicator variables for each treatment group (relative to EUC), follow-up time period (relative to preintervention), and the interaction term for Follow-Up Session $\times$ Group (relative to EUC/baseline), plus a random intercept to accommodate the within-subject clustering of data. A1c and cholesterol data were positively skewed, requiring log-normalizations before analysis. We used 500 bootstrap replications in our modeling for more precise standard error estimates of our fixed-effect terms.

\section{RESULTS}

The intervention was highly acceptable to participants, whose feedback was uniformly positive about their involvement. It is clearly feasible to deliver this intervention by telephone. We had excellent intervention retention, but lost several subjects who did not complete follow-up assessments, probably as these required inperson visits.

Both the Individual and Couples interventions yielded clinically meaningful improvements, in some cases so did EUC. Results varied by outcomes. See Table 1 for baseline, 3 and 6 month group means/SDs for the three intervention groups for all outcomes.

Change data are as follows:

Mean change in A1c Couples: $-0.37 \%$ / $-0.30 \%$ (3 months/6 months); Individual: $-0.40 \% /-0.49 \%$; EUC: $-0.42 \% /$ $-0.27 \%$. The Individual group showed the greatest declines.

Mean change in total cholesterol Couples: $-8.28 /-10.97 \mathrm{mg} / \mathrm{dl}$; Individual: $-13.83 /-25.93 \mathrm{mg} / \mathrm{dl}$; EUC: +4.24/ $+15.62 \mathrm{mg} / \mathrm{dl}$. Both intervention groups declined, the Individual group showed the greatest declines, EUC increased.

Mean change in LDL cholesterol Couples: $-.70 /-16.04 \mathrm{mg} / \mathrm{dl}$; Individual: $-10.52 /-22.24 \mathrm{mg} / \mathrm{dl}$; EUC: +8.73/ $+5.82 \mathrm{mg} / \mathrm{dl}$. Both intervention groups declined, the Individual group showed the greatest declines, EUC increased.

Mean change in waist circumference Couples: $+.39 /-0.67 \mathrm{~cm}$; Individual: $-1.72 /+1.72 \mathrm{~cm}$; EUC: $+0.41 /+0.75$ $\mathrm{cm}$. The Couples group showed the 


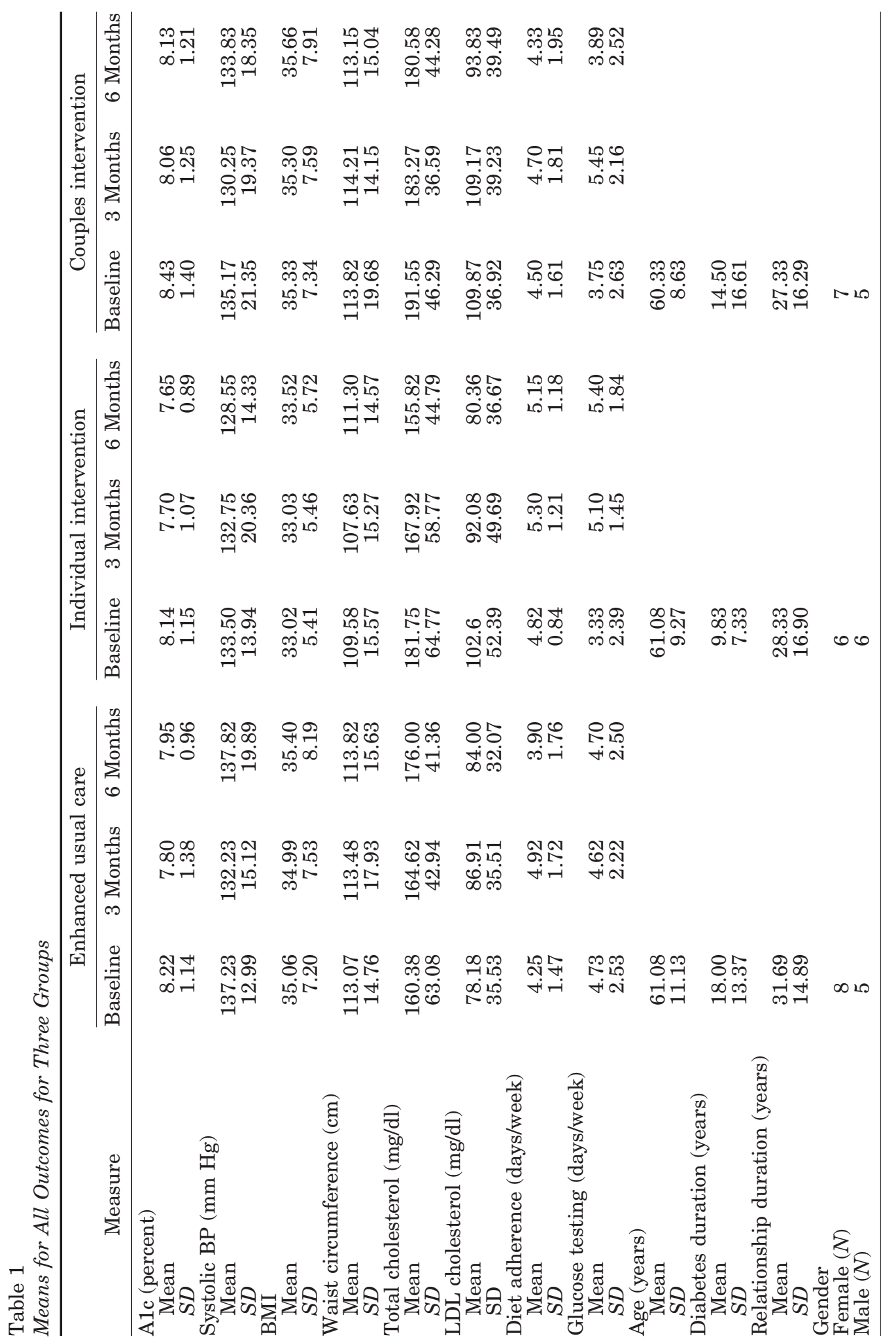


greatest decline, Individual and EUC increased.

Self-reported adherence to diet and blood glucose testing improved most for the individual group.

Our statistical analysis revealed significant treatment effects for cholesterol improvements observed at 6 months. Thus, subjects in the Individual group showed a significant decline in cholesterol relative to EUC $(p<.05)$, as did subjects in the Couples intervention $(p=.05)$. We did not find statistically significant treatment effects for A1c, systolic BP, LDL, or waist circumference.

\section{DISCUSSION}

These preliminary results reveal promising effects of both innovative, telephonedelivered interventions. Though not statistically significant, when we numerically compare the results of the Individual intervention to that involving the Couple, the Individual results are better. Glycemic control improved in all three groups, especially the Individual group.

The tentative finding that the Individual arm participants improved more than those in the Couples arm is contrary to our hypothesis. While the cross-sectional literature suggests that a couples intervention will lead to better outcomes (Schmaling \& Sher, 2000), the intervention literature is not as promising. The outcomes of pain, depression, and marital satisfaction have shown relative improvement following couples interventions (Martire, Schulz, Helgeson, Small, \& Saghafi, 2010), but none of these are analogous to a hard medical outcome like glycemic control. The studies of couples interventions for behavior change, like smoking cessation, have not supported their effectiveness (Palmer, Baucom, \& McBride, 2000; McBride et al., 2004).

It is also possible that the telephone method of delivery would have a different effect on an individual and a couples intervention. Talking one-to-one with the edu- cator might be a more intimate experience that allows for tailoring of the intervention. Sharing as a couple on a speaker-phone may not allow for the openness of the individual contact and may negatively affect the educator's ability to elicit salient issues and address them. To our knowledge, there have been no comparisons of individual to couples telephone interventions that would help us better understand this possible dynamic. Finally, the Individual group had, on average, a shorter duration of diabetes, and this may have affected the outcomes.

Therefore, it may be that our hypothesis is incorrect, and an individual intervention for Type 2 diabetes may be superior to a couples intervention. Alternatively, the couples intervention may show its promise with a longer follow-up. Most studies have had short follow-up periods and those that have longer ones often show significant regression. However, a couples intervention that yields changes in the dynamic of the relationship may demonstrate sustained behavior changes.

A major limitation of the study is the small $N$ of a pilot, so that statistical significance was difficult to achieve and these findings may not hold up with larger numbers. In addition, we noted significant individual variability. Thus, some participants in one arm did far better than some in another arm. Because individual subject data could have significantly affected measured outcomes, a much larger $N$ is needed. And, as noted, a longer follow-up is needed to note the trajectory and consistency of change. We note that several psychosocial measures (e.g., depression) were also administered to assess feasibility of the assessment protocol, but we did not analyze these data as the small number of subjects precluded meaningful analyses.

Based on this pilot, modifications to the interventions and to the assessment process were incorporated into a currently ongoing 5 year trial, including: 
1. Equivalent attention to blood glucose testing and awareness in all intervention groups. We assumed that dietary behavior changes would translate into improved glycemic control, therefore the intervention targeted these behaviors. Discussion with the interventionists, and the relative increase in blood glucose testing noted in the Individual group, suggest they may have received more attention to this behavior, perhaps because it is a self-initiated behavior and less amenable to partner collaboration;

2. Addition of a focus on activity behavior changes;

3. Training for the CDEs in emotion/ relationship focused sessions, instead of using therapists, to enhance disseminability;

4. More extensive assessments to: (a) identify patient/partner variables that predict who does and does not benefit (e.g., gender); (b) identify mediators that may influence outcomes (e.g., self-efficacy); (c) assess the impact of the intervention on partners and on the relationship;

5. The option to complete assessments at home, as assessment at the center was a barrier;

6. Expansion of recruitment sites to recruit a more diverse participant sample.

In conclusion, this pilot study demonstrates the appeal, feasibility, and potential efficacy of an innovative intervention for community diabetes patients and their partners. The pilot allowed us to develop and refine the interventions and identify those variables that should be assessed in a more comprehensive, and extended, trial. A much larger $N$ is needed to determine whether the Couples intervention is more effective in the long term than the Individual intervention. In addition, as Martire and colleagues recommend (Martire et al., 2010), this data will help us assess whether relationship quality plays a role in diabetes outcomes, whether this type of intervention has positive effects on the partner, and what underlying mechanisms might explain any changes demonstrated. Results from the ongoing trial are anticipated in 2013 and will help us better determine whether intervening with the couple, rather than the individual, results in better, and/or more lasting, improvements in outcomes. If it does add value, other interventions might also be modified to effectively and collaboratively engage the partner.

\section{REFERENCES}

Bandura, A., \& Walters, R. H. (1963). Social learning and personality development. New York: Holt, Rinehart \& Winston.

Black, D. R., Gleser, L. J., \& Kooyers, K. J. (1990). A meta-analytic evaluation of couples weight-loss programs. Health Psychology, 9, 330-347.

Brown, H., \& Prescott, R. (2006). Applied mixed models in medicine. England: Wiley.

Dale, J., Caramlau, I., Sturt, J., Friede, T., \& Walker, R. (2009). Telephone peer-delivered intervention for diabetes motivation and support: The telecare exploratory RCT. Patient Education and Counseling, 75, 91-98.

Delamater, A. M., Jacobson, A. M., Anderson, B., Cox, D., Fisher, L., Lustman, P., Rubin, R., \& Wysocki, T. (2001). Psychosocial therapies in diabetes: Report of the Psychosocial Therapies Working Group. Diabetes Care, 24, 1286-1292.

deVoogd, J. N., Knipping, A. A., deBlecourt, A. C. E., \& vanRijswijk, M. H. (1993). Treatment of fibromyalgia syndrome with psychomotor therapy and marital counseling. Journal of Musculoskeletal Pain, 1, 273-281.

Diabetes Control and Complications Trial Research Group. (1993). The effect of intensive treatment of diabetes on the development and progression of long-term complications in insulin dependent diabetes mellitus. New England Journal of Medicine, 329, 977-986.

Fisher, L. (2006). Research on the family and chronic disease among adults: Major trends and directions. Families, Systems \& Health, 24, 373-380.

Fisher, L., \& Wiehs, K. L. (2000). Can addressing family relationships improve outcomes in chronic disease? Report of the National Working Group on Family-based Interventions in Chronic Disease. Journal of Family Practice, 49, 561-566.

Garay-Sevilla, M. E., Nava, L. E., Malacarra, J. M., Huerta, R., DeLeon, J. D., Mena, A., ... Fajardo, M. E. (1995). Adherence to 
treatment and social support in patients with NIDDM. Journal of Diabetes and its Complications, 9, 81-86.

Garfield, S. A., Malozowski, S., Chin, M. H., Narayan, K. M., Glasgow, R. E., Green, L. W., Hiss, R. G., \& Krumholz, H. M. (2003). Considerations for diabetes translational research in real-world settings. Diabetes Care, 26, 26702674.

Gilden, J. L., Hendryx, M., Casia, C., \& Singh, S. P. (1989). The effectiveness of diabetes education programs for older patients and their spouses. Journal of the American Geriatrics Society, 37, 1023-1030.

Gonder-Frederick, L. A., Cox, D. J., \& Ritterband, L. M. (2002). Diabetes and behavioral medicine: The second decade. Journal of Consulting and Clinical Psychology, 70, 611-625.

Kelley, H. H., \& Thibaut, T. W. (1978). Interpersonal relations: A theory of interdependence. New York: Wiley.

Kiecolt-Glaser, J. K., \& Newton, T. L. (2001). Marriage and health: His and hers. Psychological Bulletin 127, 472-503.

Lewis, M. A., McBride, C. M., Pollak, K. I., Puleo, E., Butterfield, R. M., \& Emmons, K. M. (2006). Understanding health behavior change among couples: An interdependence and communal coping approach. Social Science \& Medicine, 62, 1369-1380.

Martire, L. M., Lustig, P., Schulz, R., Miller, G. E., \& Helgeson, V. S. (2004). IS it beneficial to involve a family member? A meta-analysis of psychosocial interventions for chronic illness. Health Psychology, 23, 599-611.

Martire, L. M., Schulz, R., Helgeson, V. S., Small, B. J., \& Saghafi, E. M. (2010). Review and meta-analysis of couple-oriented interventions for chronic illness. Annals of Behavioral Medicine, 40, 325-342.

McBride, C. M., Baucom, D. H., Peterson, B. L., Pollak, K. I., Palmer, C., Westman, E., \& Lyna, P. (2004). Prenatal and postpartum smoking abstinence: A partner-assisted approach. American Journal of Preventive Medicine, 27, 232-238.

Nathan, D. M., Singer, D. E., Hurxthal, K., \& Goodson, J. D. (1984). The clinical information value of the glycosylated hemoglobin assay. The New England Journal of Medicine, 310, 341-346.

Palmer, C. A., Baucom, D. H., \& McBridge, C. M. (2000). Couple approaches to smoking cessation. In T. Schmaling \& T. G. Sher (Eds.), The psychology of couples and illness (pp. 311-336). Washington, DC: American Psychological Association.

Patterson, J. M., \& Garwick, A. W. (1994). The impact of chronic illness on families: A family systems perspective. Annals of Behavioral Medicine, 16, 131-142.

Robles, T. F., \& Kiecolt-Glaser, J. K. (2003). The physiology of marriage: Pathways to health. Physiology \& Behavior, 79, 409-416.

Rusbult, C. E., \& Van Lange, P. A. (2003). Interdependence, interaction, and relationships. Annual Review of Psychology, 54, 351-375.

Sacco, W. P., Malone, J. I., Morrison, A. D., Friedman, A., \& Wells, K. (2009). Effect of a brief, regular telephone intervention by paraprofessionals for type 2 diabetes. Journal of Behavioral Medicine, 32, 349-359.

Schmaling, K. B., \& Sher, T. B. (2000). The Psychology of Couples and Illness: Theory, Research, and Practice. Washington, DC: American Psychological Association.

Shumaker, S. A., Schron, E. B., Ockene, J. K., \& McBee, W. (Eds.). (1998). The handbook of health behavior change. New York: Spring Publication.

StataCorp. (2009). StataCorp. Stata Statistical Software. release 11.

Toobert, D. J., Hampson, S. E., \& Glasgow, R. E. (2000). The summary of diabetes self-care activities measure: Results from 7 studies and a revised scale. Diabetes Care, 23, 943-950.

Trief, P. M., Himes, C. I., Orendorff, R., \& Weinstock, R. S. (2001). The marital relationship and psychosocial adaptation and glycemic control of individuals with diabetes. Diabetes Care, 24, 1384-1389.

Trief, P. M., Ploutz-Snyder, R., Britton, K. D., \& Weinstock, R. S. (2004). The relationship between marital quality and adherence to the diabetes care regimen. Annals of Behavioral Medicine, 27, 148-154.

Trief, P. M., Wade, M. J., Britton, K. D., \& Weinstock, R. S. (2002). A prospective analysis of marital relationship factors and quality of life in diabetes. Diabetes Care, 25, $1154-1158$.

United Kingdom Prospective Diabetes Study Group. (1998). Intensive blood-glucose control with sulphonylureas or insulin compared with conventional treatment and risk of complications in patients with type 2 diabetes. Lancet, 35, 837-853.

VonBertalanffy, Z. (1968). General systems theory: Foundations development applications. New York: George Braziler.

Wing, R. R., Marcus, M. D., Epstein, L. H., \& Jawad, A. (1991). A family based approach to the treatment of obese Type II diabetic patients. Journal of Consulting and Clinical Psychology, 59, 156-162. 